\title{
Funding and Delivering Agricultural Extension in India
}

\author{
Rasheed Sulaiman V \\ National Centre for Agricultural Economics and Policy Research, India
}

\author{
A.W. van den Ban \\ Wageningen, Netherlands
}

\begin{abstract}
The number and types of organizations providing extension services in India have shown an increase over the last two decades. The Department of Agriculture (DoA) continues to dominate extension. The DoA has been facing a number of constraints and without a total restructuring, its ability to provide services demanded by farmers is under serious doubt. The performance of private extension agents varies widely and their presence is more skewed towards well-endowed regions. A good number of farmers are willing and able to pay for quality services especially in the area of plant protection and training programs. With the changing nature of Indian agriculture, the institutional diversity in provision of extension services would increase in coming years. Public sector extension needs to make conscious efforts to learn from ongoing institutional experiments and should be restructured with the necessary skills and capacities to integrate information and expertise available in different organizations.
\end{abstract}

\section{Introduction}

Extension has been traditionally funded, managed, and delivered by the public sector all over the world. The public sector monopoly came under increasing threat in the $1980 \mathrm{~s}$ as many professionals started questioning the desirability of this situation on economic and efficiency grounds. Increasing restraints on government finances and emergence of new extension arrangements offered by the private and voluntary sectors (e.g., input companies, NGOs, farmers associations, agro-processing, etc) have accelerated the process of limiting the role of government in extension.

Decentralization, cost sharing, cost recovery, withdrawal from selected services, and contracting are some of the options exercised by various governments in privatizing extension services.

Privatizing extension, as one strategy for providing efficient services to farmers, is finding acceptance in developing countries, including India. A search for alternative funding and delivering mechanisms is currently on and a decision on how far India should pursue this strategy would depend on the type and quality of services made available by various agencies at present, especially those in private sector, and in the near future, the information needs of farmers and farmers willingness to pay for extension services.

This paper reviews the evolution of the Indian extension system, and discusses its current status by comparing the performance of the different types of extension organizations. Keeping in view the changing nature of Indian agriculture, the information needs of farmers, the increasing demand for quality services and farmers' willingness to pay for extension, the paper argues for redesigning Indian public sector extension by embracing wider expertise, decentralized management, and a culture of organizational learning. Though the paper draws its findings from the Indian situation, it is believed that lessons from this country have equal relevance to many of the developing countries that are facing similar problems in funding and delivering extension services.

\section{Evolution of the Indian Extension System} Like many other developing countries, extension services in India have been traditionally funded through public funds available from the government and delivered through a separate agency created for this purpose. Organized attempts to establish extension services in all the development blocks started after the country became independent in 1947. Pre-independent efforts had been largely local attempts, driven mainly by humanitarian ideas of a few individuals and organizations. These efforts had only limited impact and were restricted to areas where implemented. Independent India acknowledged the relevance of extension quite early, a decade earlier than organized attempts to strengthen agricultural 
research in the country. External aid for agricultural development emphasized extension in the 1950s. The two important programs, the Community Development (CD) and the National Extension Service (NES) had been clear examples of the government's commitment to provide a number of services in areas such as agriculture, health, animal husbandry and education to all sections of the society. With little progress on the agricultural front, the need for providing special attention to agriculture was realized and since the 60 s many new programs to raise agricultural production were initiated in the country.

Until the 1960s, agricultural extension was purely a function performed under the guidance of the state Department of Agriculture (DoA). A few voluntary organizations were also doing effective agricultural development work in their limited areas of jurisdiction. The Indian Council of Agricultural Research (ICAR) started getting involved in extension activities in 1966 with the National Demonstration Program. ICAR's involvement increased considerably, with the initiation and spread of Krishi Vigyan Kendras (KVK=Farm Science Centers). ICAR also initiated programs such as the Lab to Land Program and the Operational Research Program, which were merged with the KVKs in the 90s.

Establishment of radio stations and initiation of rural programs resulted in wider use of mass media for agricultural development. The print media followed suit. State Agricultural Universities (SAUs) initiated training programs (for officials and farmers), demonstrations, and exhibitions and these programs got strengthened with the establishment of Directorate of Extension in each SAU. Organizations created for promotion of specific commodities (Commodity Boards) and specific areas (Command Area Development Authority) also initiated extension activities. Extension was treated essentially as a public good, and with only public sector in the fray for technology development and transfer, the focus was on spreading the reach of extension to all parts of the country through more extension staff and a large number of programs.

The 1980s saw most of the states embracing the World Bank funded Training and Visit (T \& V) system of extension. T\&V improved the funding and human resource intensity of extension and brought a unified command for extension. The "straitjacket" approach of $\mathrm{T} \& \mathrm{~V}$, ignoring the agro-climatic and socio-economic diversity of this country, gave mixed results. The T\&V system of extension made impressive gains (in terms of productivity) in irrigated areas but failed to make any significant impact in the majority of rain-fed areas (Purcell \& Anderson, 1977). The need for a proper analysis of institutional and socio-economic factors in rain-fed areas and the importance of varied social science skills for making relevant interventions was also highlighted (Farrington et al, 1998). Since the 1980 s, more NGOs, agro-input industries, and agro-processors started taking up agricultural extension activities. Farmer associations and producer co-operatives are also presently involved in extension services in select crops and commodities. A large number of extension services are being provided by input companies, especially fertilizer companies. With an increase in rural literacy, newspapers are devoting more space for reports related to agricultural technology and development.

\section{Post-T\&V initiatives}

With external support drying up, the states started to downplay the rigor of training and visit and the 90s saw many states making experiments in providing extension services. These new initiatives include, decentralization (extension planning and control under elected bodies at the district/block level), contracting NGOs for some extension activities, adoption of a group approach (instead of the earlier individual approach), use of para-extension worker substitutes for field extension workers of the DoA, and setting up multi-disciplinary teams of scientists of State Agricultural University at the district level. Another trend is the formation of specific organizations (which are less bureaucratic, more flexible and with wider expertise) to implement special programs related to agricultural development. Formation of new organizations became essential due to the increasing inability of the line departments such as DoA to deliver results.

Another important institutional innovation presently being tried in a few selected districts has been the formation of an Agricultural Technology Management Agency (ATMA). ATMA is a registered society of key stakeholders involved in agricultural activities in a district and it is the focal point for integrating research and extension activities and 
Volume 10, Number 1

decentralizing the management of the Public Agricultural Technology System. As a society, ATMA can receive and expand project funds, enter into contracts and agreements and maintain revolving accounts that can be used to collect fees and thereby recovering operating costs (National Institute of Agricultural Extension Management, 1999). The ATMA plans and implements programs based on a Strategic Research and Extension Plan prepared at the district level, and also based on suggestions from the Farmers Advisory Committee. ATMAs are encouraged to recover at least parts of their operational expenses by selling services. The preliminary experiences of some of the ATMAs have been encouraging. One of the very recent initiatives taken by the government is to launch agri-clinics. The plan is to establish 5000 agriclinics through unemployed agricultural graduates, which is about one for 20,000 farmers. The program is financed through bank loans, while the government would provide $25 \%$ of the cost as a subsidy. The agri-clinics would provide testing facilities, diagnostic and control services, and all kinds of agri-consultancy services, on a payment basis.

\section{Current Status}

A number of organizations are currently providing extension services in the country. Their presence is however highly skewed towards well-endowed regions and the intensity in terms of expenditure, human resource allocation, and contacts vary widely (Table 1 ). The table reveals that only three agencies have a significant presence in extension, namely the state Department of Agriculture (DoA), farmer associations, and producer co-operatives. Except these and the Krishi Vigyan Kendra, others spent less than Rs. 1(US \$ 0.02) per hectare for extension activities. The contact intensities are the highest in farmer associations, followed by producer co-operatives. Only producer cooperatives, farmer associations and DoA have reasonably good technical manpower: cultivator (TC) ratio (at least one technical person for less than 1,500 farmers). Farmer associations and producer co-operatives exist only for few crops/commodities. But wherever they exist, they are the most effective in reaching farmers producing these crops/commodities. Farmer associations and producer co-operatives manage mostly with their own funds and still are high on spending for extension. Initiating, sustaining, and promoting farmer organizations should thus be a high priority for public sector extension in India.

The main extension function performed by DoA officials is the delivery of technical messages to individual farmers or farmers groups through visits to specific locations in the officials' areas. These visits are not regular because of pre-occupation with implementation of a number of central and state sector schemes having input/subsidy delivery. Performance of the DoA is also adversely affected by depleting operational support and poor technical background of the majority of its employees. However, the DoA is the only institution available throughout the country for farmers to consult for information, though their role in delivering information in non-food grain crops is limited. The DoA is still the primary source of information for the majority of farmers though their satisfaction with this service varies widely. Farmer dependence on other farmers and input dealers as sources of information continues to be high (Sulaiman \& Sadamate, 2000). Other government departments, such as Animal Husbandry and Horticulture give some attention to extension, but their main focus is on health care or distribution of seeds. 
Volume 10, Number 1

Table 1

Performance indicators of extension organizations (Average)

\begin{tabular}{|c|c|c|c|c|c|}
\hline \multirow[b]{2}{*}{ Organization } & \multicolumn{3}{|c|}{$\begin{array}{l}\text { Extension expenditure (Rs/ha) } \\
\text { (Rs. } 1=0.02 \text { US Dollar) }\end{array}$} & \multirow[b]{2}{*}{$\begin{array}{l}\text { Contact Intensity } \\
\text { (hr/target pop.) }\end{array}$} & \multirow[b]{2}{*}{$\begin{array}{l}\text { Tech. Manpower } \\
\text { Cultivator ratio }\end{array}$} \\
\hline & Total & $\begin{array}{l}\text { Excludin } \\
\text { Salary }\end{array}$ & Extension & & \\
\hline Department of Agriculture & 44.94 & 4.57 & - & 0.400 & $1: 1332$ \\
\hline Directorate of Extension & 0.74 & - & - & 0.010 & $1: 63500$ \\
\hline Krishi Vigyan Kendras & 5.58 & 4.21 & - & 0.090 & $1: 54255$ \\
\hline Farmer Associations & - & - & 46.97 & 3.010 & $1: 1080$ \\
\hline Producer Co-operatives & - & - & 34.10 & 1.960 & $1: 928$ \\
\hline Research Institute & - & - & 0.24 & - & - \\
\hline Input Companies - Seeds & - & - & 0.53 & 0.002 & $1: 57823$ \\
\hline Input Companies -Fertilizer & - & - & 0.47 & 0.014 & $1: 5,41723$ \\
\hline NGOs & 18.59 & - & - & 0.490 & $1: 13871$ \\
\hline Consultancy Services & - & - & - & 0.013 & $1: 96555$ \\
\hline Commodity Board & $824.20^{*}$ & - & - & 0.570 & $1: 2876$ \\
\hline Marketing Boards & 0.19 & - & - & 0.002 & $1: 492800$ \\
\hline Media-AIR & 0.15 & - & - & - & - \\
\hline Media-Print & 1.73 & - & - & - & - \\
\hline
\end{tabular}

Note. *A good amount of this funding goes to subsidies and administrative expenses.

From "Privatizing agricultural extension in India" by V. R. Sulaiman and V. V. Sadamate, 2000, Policy paper 10, New Delhi: National Centre for Agricultural Economics and Policy Research.

Farmer associations and producer cooperatives provide a large number of services, including extension, to farmers. The case is the same for Commodity Boards. The field extension activities of the Directorate of Extension of the State Agricultural Universities, agricultural colleges, and research stations of SAU/ICAR are restricted to a few villages around their location. KVKs are organizing a number of vocational training programs for farmers. ICAR is presently establishing 40 Agricultural Technology Information Centers (ATIC) attached to SAU/ICAR institute, wherein a single window facility provides farmers with information, inputs, and services. The service of ATIC could be optimally used by only those residing in the district or nearby districts and their location within public sector institutions often prevents transfer of information and technologies developed outside the public sector organizations.

NGOs are involved in a number of activities. With very few exceptions, most of the NGOs are small and their activities, though intensive, are restricted to a few beneficiary farmers or at the most to a few villages. Consultant services providers are few and are mostly private ventures found in high value crops. The potential of media is under-utilized at present, but agricultural programs of some of the private TV channels and print media have high impact as source of information. The use of the Internet for providing information is starting, and the National Institute for the Management of Agricultural Extension is taking a lead in this direction (National Institute of Agricultural Extension Management, 2001). Input companies do not have full-time extension staff. Their marketing staff organizes extension activities such as demonstrations, seminars, etc. with the support of dealers and at times in collaboration with DoA.

\section{Towards a Pluralistic Extension Approach}

As seen from earlier discussions on post $T \& V$ initiatives, there have been many attempts to deliver extension service through organizations other than the DoA and State Agricultural Universities. A search for alternate delivery and financing mechanisms began with the increasing realization that "public extension by itself cannot meet the specific needs of various regions and different classes of farmers" (Department of Agriculture and Co-operation, 2000). The draft policy framework for Agricultural Extension also says that "the policy 
environment will promote private and community driven extension to operate competitively, in roles that complement, supplement, work in partnership and even substitute for public extension" (Department of Agriculture and Co-operation, 2000).

Though the above policy declaration seems to portray a genuine response to the changing times, the level of preparedness by the public sector to work in a multi-institutional environment does not look encouraging. The collaboration of government and nongovernmental organizations for sustainable agricultural development experimented in Rajasthan revealed a number of issues, including the pervasive perception in government that NGOs should merely be contracted to provide services, but a perception among NGOs that their strength lies more in mobilizing people to make demands on the system (Alsop et al., 2000 ). Though the private sector involvement in agricultural extension is not uniform across the country, there are several districts where a number of organizations providing diverse services are working in isolation without any level of interaction. While restructuring extension to operate effectively in an increasingly multi-institutional era, the following aspects need to be kept in view.

\section{Changing Nature of Indian Agriculture}

Despite its past achievements, Indian agriculture continues to face serious challenges because of the ever-increasing population, declining land and water availability and degradation of natural resources. A generally unfavorable price regime and low value addition have resulted in abandoning of farming and increasing migration from rural areas. Changes in recent years, not least the increasing penetration of markets into rural areas and the need to tailor products to ever more stringent market requirements mean that extension support must now address a broader range of aspects, including:

1. What technological options can be used profitably in his/her situation keeping in view the potential resource constraints in terms of land, capital, labour and knowledge?

2. How to manage various technologies? (How to make optimal use of new inputs on the farm?)
3. How and when to change farming systems? (Diversifying from crop production to mixed farming or vegetable or animal production.)

4. For which type of products is there a good demand in the market?

5. What are quality specifications for the produce and how to achieve them? (e.g., for export markets, organic farming)

6. How, when, where, and under which conditions to buy inputs and sell products?

7. How to make decisions collectively on resource use and marketing?

8. How to find quickly the most relevant and reliable knowledge and information?

9. What are the feasible off-farm income generation options available for members of the farm family and how could they depend on them?

10. What are going to be the implications if input subsidies are phased out and or if the trade in agricultural products is liberalized? (van den Ban, 1998)

Though many of the above mentioned aspects have been always relevant, public sector extension has been focusing only on the dissemination of production technologies, but this approach is no longer sufficient. The current priorities of Indian agriculture include conservation of soil, water and bio-diversity; diversification to horticulture; value added products; development of rural infrastructure and agro-enterprises; and creation of employment in rural areas (Department of Agriculture and Co-operation, 2002). To make good decisions, farmers need information from different sources and often need help to integrate the information. Due to its sole dependency on knowledge and information mainly from SAUs and to some extent from ICAR institutes, public sector extension continues to provide information only on technologies generated in these research stations and passed on to farmers.

The emphasis continues to be on food grains, though broad basing of agricultural extension (including messages for other crops/enterprises) is an accepted philosophy. Public extension should give increasing attention to access and integrate information and expertise from a wider range of sources (e.g., private sector laboratories, farmers, NGOs, processors, market analysts, traders, and consumer groups), to meet the changing needs of farmers. No other organization other than the state Department of 
Agriculture has the overall capacity to play this role in the Indian context. Moreover, it is virtually impossible for the majority of small farmers in the country to contact a number of organizations to obtain all this information.

\section{Willingness to Pay}

Almost all services provided by public sector extension have been traditionally free. However, the situation started changing since late 80 s. Making clients pay at least a part of the cost of providing service became a part of the government thinking. The increasing costs of providing services and the government's unwillingness to fully support extension activities forced many organizations in the public sector such as DoA, research organizations (ICAR and SAUs) and training organizations (KVKs) to identify services that could generate resources. Thus services, such as soil testing and input cost of field demonstrations came under a payment basis. As more farmers started to diversify to other crops than food-grains, their requirement for agricultural information changed qualitatively. The DoA has been focusing over the years on food-grains and their expertise on other crops and enterprises is limited. In response to this growing demand, at least in a few places, individuals and organizations have been coming forward to provide consultancy services for a fee.

In a study conducted among 720 farmers from three states of India, Sulaiman and Sadamate (2000) found that about $48 \%$ of farmers expressed willingness to pay for agricultural information. The marketing approach followed by Ingram (1992) was used to understand the willingness of farmers to pay for extension services. In this method, farmers' opinion on extension services and pricing policies are elicited through personal interviews. To identify the variables that are important in discriminating between those who are willing to pay and those not willing to pay and to classify them, on the basis of differences in the selected characteristics, the linear discriminant function was used (Sulaiman \& Jha, 2000). Farmers' willingness to pay has not been uniform across producers. The level of satisfaction with the primary source of information was found to be the most important factor that discriminates farmers who are willing and not willing to pay for extension services (lower the satisfaction with the primary source of information, the more willingness to pay for quality extension services from elsewhere if made available). Other important variables are those related to area and income. Farmers having higher total area and higher area under non-food grains were more willing to pay for better quality agricultural information. The majorities of subsistence farmers growing food grains in India have difficulty in paying for extension and need to be supported through public funded extension.

Farmers were found to be willing to pay for quality extension services in the area of plant protection and training programs. One important condition for the paid services is the farmers' insistence on field visit based advice. Farmers as a group are also willing to share the costs for bringing expert advice. The willingness to pay among farmers was more in non-food grain crops, especially, horticultural crops (fruits, vegetables, flowers and spices) and oilseeds.

Considerable scope exists for initiating paid extension services in agriculture. DoA and other agencies in the public sector should initiate problem-solving consultancy services and needbased training programs, especially in non-food grain crops. To begin with, these services could be provided at the district or sub-district level by pooling the expertise of more qualified and trained personnel available with the DoA and the SAUs. The fees collected could be a potential source of funds for the DoA to meet its declining operational funding.

Though roughly $50 \%$ of the sample farmers are willing to pay for quality services, it should be borne in mind that pay-worthy services are generally absent in India. In most of the rain-fed and far-flung districts, even the DoA has difficulties in maintaining a minimum number of field staff for routine activities. The challenge is therefore in creating quality services to meet the increasing demand. The government can facilitate emergence of quality services through creation of new units within the DoA or through strategic placement of its funds with other extension providers. 
Volume 10, Number 1

Extension's Role in the Changing Indian Context

Extension has to perform a muchexpanded role than what it had been performing hitherto. Farmers need a wide range of services related to technology (production and processing), quality, access to markets, price information, and business development. Public sector extension also has to improve the ability of farmers to collectively find solutions to their problems. Public sector extension has to initiate, nurture, and network existing and new institutions to provide a broad range of services. The DoA, which should have ideally performed this role, is unfortunately not organized to do so. Studies that examined Research-Extension linkages have clearly shown the difficulties of maintaining linkages between the research and the extension systems (Kaimowitz, 1991). The organizational structure of the government extension machinery was designed about four decades ago with the objective of increasing food grain production. There is a need to restructure the DoA with new expertise and skills and with a new set of operational procedures, which are less hierarchical and more flexible, to respond to the emerging needs of farmers at the local level and to improve the cooperation among different government departments and other development agencies. Extension needs to take up increasingly the role of enabler, though its role as a doer should also continue but in a qualitatively different way. The first step could be the identification of the different elements in the Agricultural Knowledge and Information System and redesigning this system in a way that information flow among these elements is improved (Sulaiman \& Hall, 2002). Clearly this redesign is something that has to be devised locally with arrangements evolving over time and requires a learning approach where interventions are inherently experimental and iterative. Designing extension organizations as learning organizations (van den Ban, 1997) is important. Indian farmers have limited possibilities to influence the quality of the services provided by extension organisations as it continues to be funded fully by the government. Katz (2002) noted based on experience with extension in many countries that this inability to influence public sector extension is related to the way extension is funded. Creation of alternate organisational structure such as ATMA with participation of different stakeholders to decide extension priorities and to generate resources for extension is expected to make the extension agenda farmer accountable. Public sector extension however needs to have a wide range of competencies to perform new roles.

\section{Future Roles and Competencies}

Extension needs to expand its role from technology transfer to include roles such as problem solving, education, and human development. To perform these roles, it needs an increasing level of skills (van Beek, 1997). None of these four functions should be left out when designing or evaluating an extension project. To remain relevant and useful in the years to come, the public sector extension system has to strengthen its understanding on technology, markets, prices, and policies either by recruiting specialists or by contracting out these services (Figure 1). Extension systems should also have competence in evaluating a wide range of information and communicating this information to farmers through a wide range of media. Apart from obtaining and integrating information from a number of sources for providing information, extension has to provide solutions to specific field problems and initiate measures to organize farmers. Extension staff needs an increasing level of social science skills related to group formation, leadership development, conflict resolution, and inter-group negotiation to work effectively in mobilizing and organizing farmer groups. 


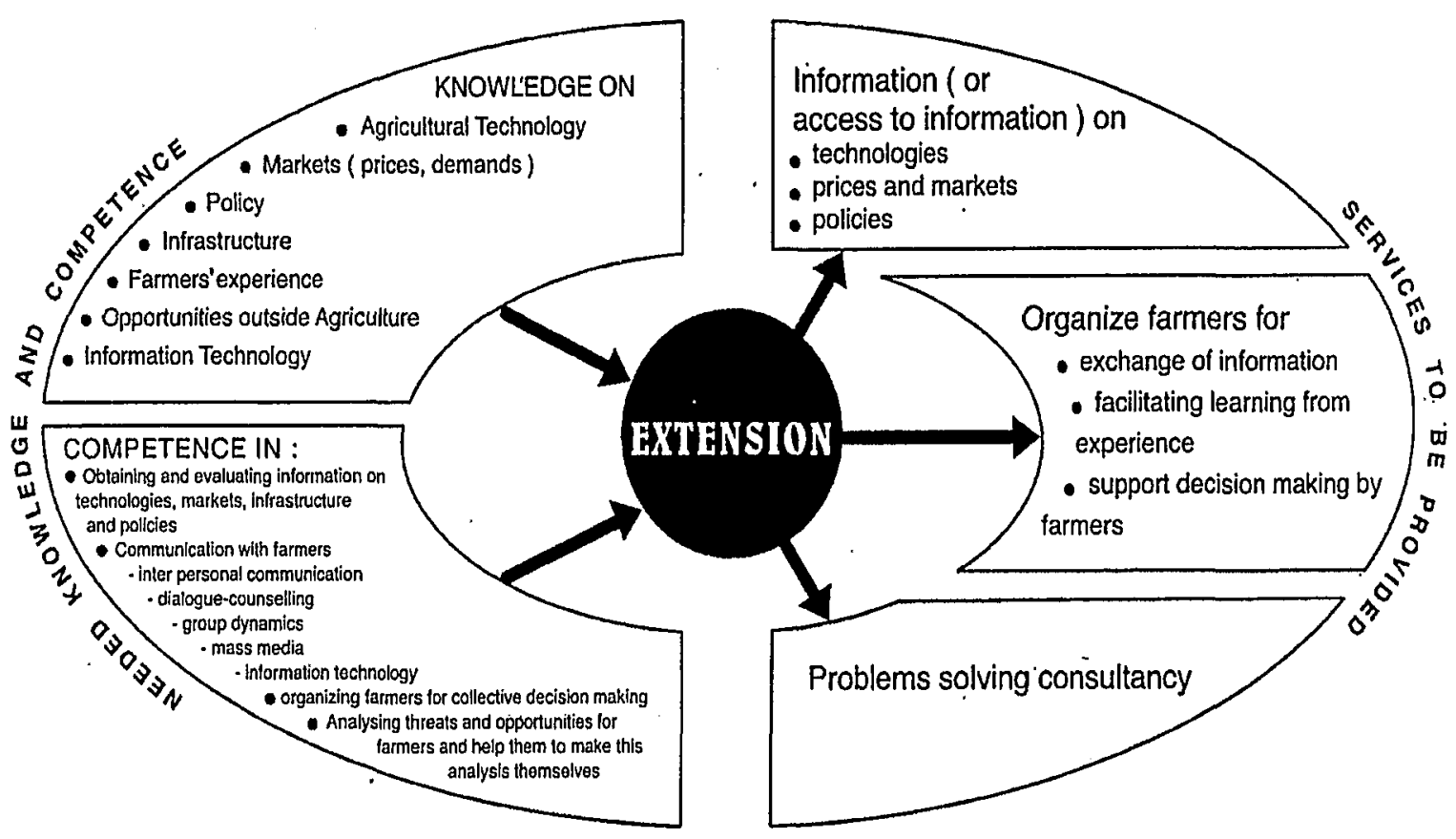

Figure 1. Future roles and competencies for extension.

From "Agricultural extension in India: The next step," by V. R. Sulaiman and A.W. van den Ban, 2000, Policy brief 9. New Delhi: National Centre for Agricultural Economics and Policy Research.

To perform these new roles, public sector extension needs a sound human resource management strategy including a clear analysis of the present and future knowledge and skills needed by the organizations, job design for individuals and teams, matching qualifications with the position required, clear policies on recruitment, selection, placement and promotions and types of training required on the job. Human resource development has been much talked about and the time is ripe for a continuous HRD program to be put in place. But the background and expertise of trainers need emphasis. In several cases, posts of trainers are being filled through promotion from the lower ranks of the DoA. Freedom to hire necessary expertise from other institutions has not been successful due to a low honorarium and lack of adequate funds. Creating autonomous training institutions may help in obtaining experienced and capable faculty for training extension staff.

\section{Organizational and Management Reform}

Organizational and management reforms are long over due in the public extension system. The needed reforms include decentralization of responsibility; delegation of authority to district managers and teams; autonomy in routine decision making; project-based funding; jurisdiction for contracting out services, expertise and facilities; and a separate budget for operational expenditure. These recommendations necessitate a reduction in the number of programs designed by the central government and implemented under uniform operational guidelines. More flexibility is now given to states to choose central sector programs. This flexibility needs to be extended to the district and block levels. It would be worthwhile to conduct a professional Organizational, Management and Financial review of the DoA at the state and district level to develop systems for improved performance. Performance evaluation of externally funded extension programs would also help to identify factors contributing to successful performance. 


\section{Conclusions}

Public sector extension has to play a much greater role in the changing agricultural situation in India than it has played so far. Public sector extension has to provide information and advice to farmers not only on technologies, but also on solutions to specific field problems, markets, prices, quality, and implications of policy changes. Public sector extension also has to organize farmers to take collective action to adopt new technologies, solve problems, and increase income from agriculture. To perform these roles, public sector extension has to reorganize its structure and functions by embracing wider expertise, decentralizing management, and nurturing a culture of organizational learning. A large number of organizations are currently providing extension services in the country. Public sector extension could considerably improve its effectiveness through developing partnership with many of these new organizations that have emerged in the extension scene in the last two decades. Both economic and social reasons justify public financing of extension in the Indian context, but some of these services could be better delivered outside the public machinery.

The same is the case with many developing countries which are also experimenting with options for financing agricultural extension (Beynon et al, 1998; Katz, 2002). Attempts to enhance the capacity of national extension systems in these countries should take into consideration the diversity of organisations that are providing different extension services and the potential for improving the relationships among them. Several opportunities for the successful integration of the efforts of public and private organizations for funding and delivering extension services exist. Extension managers and policy makers needs to explore these options for providing better extension services to farmers to meet the emerging challenges.

Note. A previous version of this paper was presented at the $15^{\text {th }}$ European Seminar on Extension Education in Wageningen, the Netherlands (29-8-2001).

\section{References}

Alsop, R., Gilbert, E., Farrington, J., \& Khandelwal, R. (2000). Coalitions of interest: Partnership for process of agricultural change. New Delhi: Sage publications.

Beynon, J., Akroyd, S., Duncan, A., \& Jones, S. (1988). Financing the Future Options for Agricultural Research and Extension in Sub-Saharan Africa, Oxford, England: Oxford Policy Management.

Department of Agriculture and Co-operation. (2000). Policy framework for agricultural extension (draft). New Delhi: Extension Division, Department of Agriculture and Co-operation, Ministry of Agriculture, Government of India.

Department of Agriculture and Co-operation. (2002) National Agriculture Policy, Retrieved May, 2002 from http://agricoop.nic.in/agpolicy02.htm.

Farrington, J., Sulaiman, R. V., \& Pal, S. (1998). Improving the effectiveness of agricultural research and extension in India; An analysis of institutional and socio-economic issues in rain-fed areas, Policy paper 8, New Delhi: National Centre for Agricultural Economics and Policy Research.

Ingram, P. (1994). The United Kingdom Experience in the Privatization of Extension. In Cornellis de hann \& Anderson, J.R. (Eds.) Public and Private Roles in Agricultural DevelopmentProceedings of the Twelfth Agricultural Sector Symposium, (pp-51-58). Washington, DC: The World Bank

Kaimowitz, D. (1991). The evolution of links between extension and research in developing countries. In Rivera, W.M \& Gustafson, D.J. (Eds.), Agricultural extension: worldwide institutional evolution and forces for change, New York: Elsevier.

Katz, E. (2002). Innovative Approaches to financing extension for agricultural and natural resource managementConceptual considerations and analysis of experience. Lindau: Swiss Centre for Agricultural Extension. 
National Institute of Agricultural Extension Management. (1999). Agricultural Technology Management Agency, (MANAGE-NATP Series-2). Hyderabad: MANAGE.

National Institute of Agricultural Extension Management. (2001). Proceeding of the National Workshop on Cyber Extension, MANAGE Bulletin, Vol. 7, Issue 1.

Purcell, D. L., \& Anderson, J. R. (1997). Agricultural Extension and Research: Achievements and Problems in National Systems. Washington, DC: The World Bank.

Sulaiman, V. R., \& Sadamate, V. V. (2000). Privatizing agricultural extension in India, Policy paper 10, New Delhi: National Centre for Agricultural Economics and Policy Research.

Sulaiman V. R., \& Jha, D. (2000) Determinants of demand for paid farm extension services in India: A discriminant function approach. Afro-Asian Journal of Rural Development, 33(2), 57-67.
Sulaiman, V. R., \& van den Ban, A.W. (2000) Agricultural extension in India; The next step, Policy brief 9, New Delhi: National Centre for Agricultural Economics and Policy Research.

Sulaiman, V. R., \& Hall, A. J. (2002). Beyond technology dissemination-Can Indian agricultural extension re-invent itself? Policy Brief 16, New Delhi: National Centre for Agricultural Economics and Policy Research.

Van Beek, P. G. (1997). Beyond technology transfer, European Journal of Agricultural Education and Extension, 4 (3), 183-192.

Van Den Ban, A. W. (1997). Successful agricultural extension agencies are learning organizations. In Samanta, R.K. \& Arora, S.K. (Eds.), Management of Agricultural Extension in Global Perspectives, New Delhi: B.R Publishing Corporation.

Van Den Ban, A. W. (1998). Supporting farmers decision making process by Agricultural Extension, Journal of Extension Systems, 14, 55-64. 